\title{
PREDICTIVE MODEL FOR THE ASSESSMENT OF VOCS EMISSION IN OPEN DUMPSITE USING GENERALIZED LINEAR MODEL
}

\author{
A. Ighodaro ${ }^{1 *},{ }^{1}$ J. M. Okuo ${ }^{1}$ and D. Okuonghae ${ }^{1}$ \\ ${ }^{1}$ Analytical/ Environmental Research Laboratory, Department of Chemistry, University of Benin, Benin \\ City, Nigeria. \\ ${ }^{2}$ Department of Mathematics, University of Benin, Benin City, Nigeria. \\ Corresponding Author's email: nobleighos@yahoo.com Tel.: +2348039210070 \\ Received 25 June 2020; accepted 05 July 2020, published online 28 August 2020
}

\begin{abstract}
Ambient air quality assessment and regulations plays an important role in air quality management. Forty-five (45) air samples were collected for both wet and dry season of the year (October 2016September 2017). The air samples were collected by passive sampler (Drager ORSA 5). The samples were analyzed for VOCs, PM 2.5 and some elements according to standard methods. In this study, a method to predict aromatic VOCs concentrations in the urban outdoor environment was developed based on the Generalized Linear Models (GLM). The method is based on the relationship developed between atmospheric concentrations of air pollutants and meteorological variables (i.e. ambient temperature, relative humidity and wind speed). The developed GLM model considers VOCs concentrations as a dependent variable, and $P M_{2.5}$ pollutants and meteorological parameters as explanatory independent variables. A comparison of obtained prediction with observed values showed that the developed model indicated good performance in estimating VOCs concentration. It should be mentioned that the puissance of the model developed is a function of the covariates. This observation suggest that the model with predicted meteorological variables can be engage in environmental management system were data are not readily available.
\end{abstract}

Keywords: VOC, Generalized Linear Models (GLM), Open Dumpsite, Benin City

\section{Introduction}

Aromatic Volatile Organic Compounds (AVOCs) are relatively minor components of the atmosphere but are widely recognized to play important roles in air quality [1]. Volatile Organic Compounds (VOCs) are important outdoor air toxins suspected to increase chronic health problems in exposed densely populated areas [2, 3]. "Haagen-Smit (1995) in his studies of Los Angeles' smog 50 years ago recognized that organic pollutants released into the atmosphere are as a result of anthropogenic activities" [4]. VOCs consist mainly of atmospheric hydrocarbons that contribute to ozone and other photochemical oxidants formation in the troposphere [5]. Most typical of VOCs pollutants in the air are benzene, toluene, ethylbenzene, and xylene respectively [6, 7]. Toxic and carcinogenic human health effects, global greenhouse effect enhancement and contribution to depletion of stratospheric ozone are some of the various recognized effects of VOCs [8]. In the United States, 35-55\% of the outdoor air cancer risks are accounted for by ambient VOCs [9]. Furthermore, the published "Hazardous Air Pollutants (HAPs) List" by the US-EPA [10] approximated $70 \%$ of 189 HAPs as species of VOCs. Workers and neighbourhood residents are exposed to the mutagenic and carcinogenic dangers posed by the emission of these species [11, 12] and require strict regulation and control. Daily levels of pollutant concentration and admissions of respiratory or cardiovascular origins have been significantly associated with the VOCs had been reported [13, 14]. Despite the advanced waste management techniques, currently available, increased human activities continue to generate an increasing amount of solid wastes worldwide. Urbanization, industrialization and agricultural activities necessitated by fast-paced population growth and changes in consumer habits have led to the generation of considerable heavy amounts of solid wastes [15, 16] and consequently, Industrial and municipal waste generation and 
management have been a problem of major concern worldwide.

Findings from several studies have shown that waste combustion of semiconductors, chemicals and plastics are the major sources of atmospheric VOCs [17-22]. Additionally, several species of VOCs, which worsen air quality and cause a reduction in atmospheric visibility, are also ground-level ozone formation precursors, contributed mainly by industrial factories and on-road mobiles [23]. To this end, Edo State, Nigeria, where these studies took place has a huge problem concerning waste disposal due to the increase in industrial and vehicular activities.

Understanding urban atmospheric photochemical air quality requires VOCs monitoring as atmospheric degradation of VOCs significantly contributes to air pollutant generation. Open dumpsites are known to emit large amount of VOCs and $\mathrm{PM}_{2.5}$ into the surrounding ecosystems [16]. In the nearest future, accurate prediction of pollutants (VOCs and $\mathrm{PM}_{2.5}$ ) will be key in the search for strategies to minimize stratospheric ozone loss and greenhouse gas emissions. While many studies have attempted predicting concentrations of $\mathrm{PM}_{2.5}$, in an outdoor environment [24]. Little or no studies have been reported for the VOCs. Models predicting VOCs with respect to fine particulates concentration becomes necessary, in this regard, have not be investigated. In this research work, the Generalized Linear Model (GLM) was developed to predict the ambient concentration of VOCs in an open dumpsite [24].

\section{Methodology}

\section{Linear Regression Model}

The generalized linear model (GLM) was used to build a system to quantify PM concentrations based on known values of other outdoor air pollutant concentrations [24]. "GLM is based on the assumption that there are $\mathrm{K}$ independent values $Y_{1}, \ldots, Y_{k}$, from a variable of interest or response variable (effect) that follows an exponential family distribution with the expected value

$E\left(Y_{i}\right)=u_{i}{ }^{2}[25]$.

Considering $\mathrm{K}$ vectors

$X_{i}=\left(\begin{array}{llll}1 & X_{i 1} X_{i 2} & \ldots & X_{i p}\end{array}\right)^{t}, i=$

$1, \ldots, \mathrm{K}$, containing the values of $\mathrm{P}$ explanatory variables, independent or covariates (variables that are possibly predictive of the outcome understudy). Considered also a link differentiable function $\mathrm{g}$, such that:

$g\left(u_{i}\right)=X_{i}^{t} \beta, i=1, \ldots, K$

Where $\left(\beta=\beta_{1}, \beta_{2} \ldots \beta_{p}\right)$ are coefficients of the predictors to be estimated. Thus, if for the factor $\mathrm{g}$, we consider the principal function we have:

$$
\begin{aligned}
& g\left(\mu_{i}\right)=\mu_{i} \\
& \text { then } \\
& u_{i}=E\left(Y_{i}\right)=X_{i}^{t} \beta
\end{aligned}
$$

"The model so obtained is the Gaussian linear regression model. Alternatively, given the function $\mathrm{g}$ as a logarithmic function and $\mathrm{Yi}$ has a Poisson distribution, then the model approximates to a Poisson regression model where the constant $\beta_{i}$ is the effect of variable $X_{i}$ in $g\left(\mu_{i}\right)$ " [23].

\section{STUDY AREA AND DATA CHARACTERISTICS}

\section{Study Area}

The study was carried out at a major dumpsite in Ikhueniro. Ikhueniro is located in Uhunmwode Local Government Area of Edo State with its Administrative headquarters at Ehor. Ikhueniro dumpsite is the largest and the major open dumpsite in Benin metropolis The dumpsite lies between latitude $06^{\circ} 19^{\prime} 38.1^{\prime \prime} \mathrm{N}$ and longitude $005^{\circ} 44^{\prime} 5.2^{\prime \prime} \mathrm{E}$. Uhunmwode has an area of $2,033 \mathrm{Km}^{2}$ and population of about 121,749 with a population density of $59.89 \mathrm{Km}^{2}$ according to 2006 census. The distance of the sampling location from the city centre is about $14 \mathrm{Km}$ 


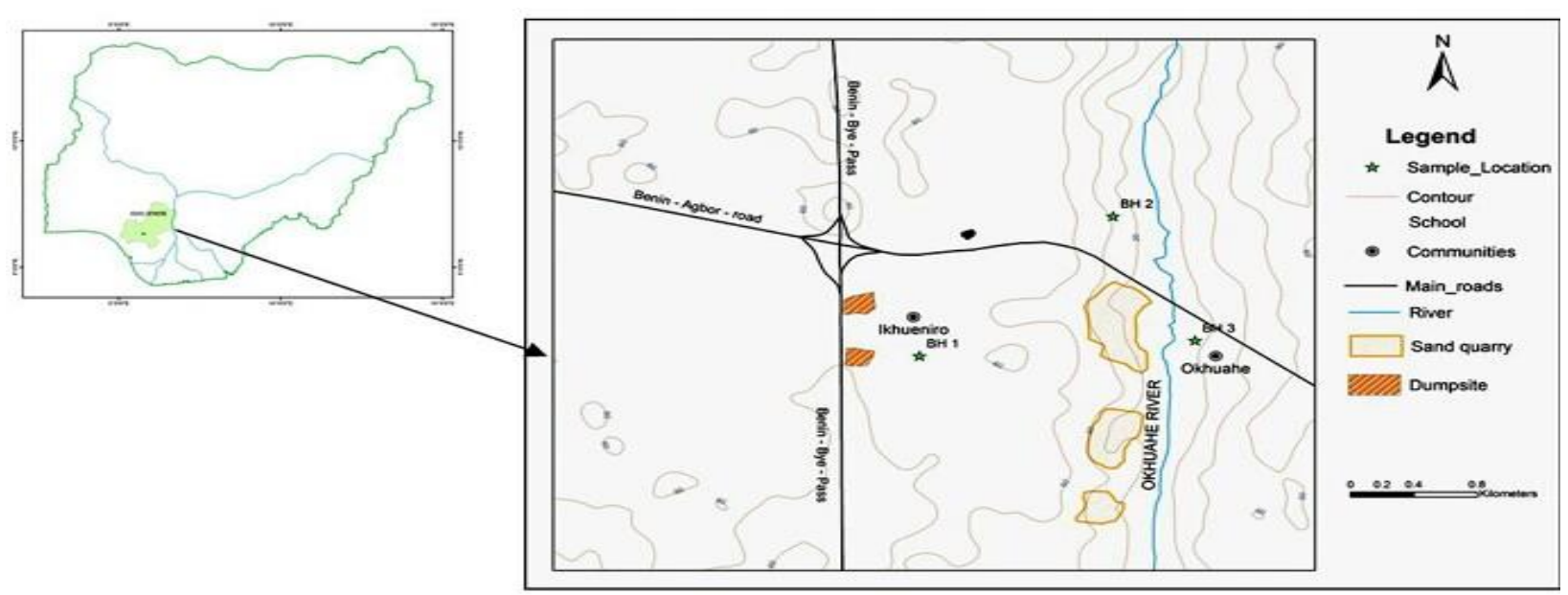

Figure 1: Map of Edo State Showing Ikhueniro dumpsite and Neighboring Communities

\section{Sampling Device and Collection of Ambient VOCs}

Ambient air samples were collected using (ORSA 5 diffusion tubes) Drager safety, Lubeck Germany. The diffusive passive sampler fulfilled many of the logistical requirements of an ideal ambient monitor [26]. A validation process for diffusive sampler has been performed $[27,28]$

\section{Sampling Device and Collection of Ambient $\mathbf{P M}_{2 \cdot 5}$}

The fine Particulate Matter $\left(\mathrm{PM}_{2.5}\right)$ was collected using Casella Cel-712 Micro dust Pro Real-time

Dust Monitor with Polyurethane Foam (PUF) and a Glass Fibre Filter (GFF). The sampler was connected to a pump with a flow rate of $2 \mathrm{~L} / \mathrm{min}$ for a sampling period of 8 hours/day. A sizeselective Polyurethane Foam (PUF) fixed in the sampler probe served as a collecting medium and a glass fibre filter also fitted in the probe collected $\mathrm{PM}_{2.5}$ screened through the PUF. Calibration of the Casella Cel-712 Micro dust sampler was done to ensure reproducible results. Method blanks were measured along with samples, and all results reported here were blank- subtracted.

\section{Meteorological data}

During the sampling period, a humidity/temperature meter, with resolutions of $0.1 \% \mathrm{RH}$ and $0.1{ }^{\circ} \mathrm{C}$ (model RS 1364, RS Components Ltd, UK) was used to simultaneously measure relative humidity (\%) and average monthly air temperature $\left({ }^{\circ} \mathrm{C}\right)$ while wind speeds were measured with an LM-8000 anemometer with a resolution of $0.1 \mathrm{~ms}^{-1}$ (Heatmiser UK Ltd.)

\section{Model Parameters}

Total of forty-five (45) $\mathrm{PM}_{2.5}$ samples were documented (October 2016- September 2017) the meteorological variables temperatures, wind speed, and relative humidity were recorded (Table 1 and Table 2). The mean temperature range used in the model was $\left(31.79{ }^{\circ} \mathrm{C}\right)$ and the mean annual relative humidity was $(58.95 \pm 8.72 \%)$ while wind speed $(2.02 \pm 1.98)$

\section{Model Development}

Using the GLM function in MATLAB, we seek to find a relationship between the concentration of the VOCs (as the output response) $\mathrm{PM}_{2.5}$ and variables, temperature $\left(\mathrm{Temp},{ }^{0} \mathrm{C}\right)$, relative 
humidity (RH, \%) and wind velocity (WV, m/s) (as input responses). One year data (October 2016- September 2017) for the study of VOCs concentration and the relationship with $\mathrm{PM}_{2.5}$ and the metrological variable was used to build a generalized linear model. The GLM models were used to investigate the complex associations between the concentrations of $\mathrm{PM}_{2.5}$, meteorological and VOCs in Ikhueniro open dumpsite in Benin City

[VOCs] $=\alpha+\beta_{1} \operatorname{var}_{1}+\beta_{2} \operatorname{var}_{2}+\beta_{3} \operatorname{var}_{3}+\cdots+\beta_{1}$ $\operatorname{var}_{1}$

From the results, VOCs can be estimated as the product of the exponential terms. The first term is the intercept of the regression model while other terms are coefficients of the variables, derived from the GLM model as explained above. This methodology was applied to the developed model (A). There was an indication of strong and moderate correlation between benzene and other aromatic VOCs. Based on this strong linear relationship we considered benzene in place of aromatic VOCs. These considerations are shortly resumed in (Table 3 ). The coefficients $\beta_{\mathrm{i}}$ 's calculated with the developed method for the model is given in the equation below

\section{VOCs $=88.0760-0.4406[$ Temp $]-$ $0.6394[R H]-5.0365[\mathrm{WV}]-0.0061\left[\mathrm{PM}_{2.5}\right]$

\section{Analysis Variables of the Model}

Sampled data from Ikhueniro Dumpsite in Benin City was used to test the model. Figure 2 shows the scatterplot of measured aromatic VOCs (MAVOCs) versus predicted aromatic VOCs (PAVOCs) concentration by the developed model

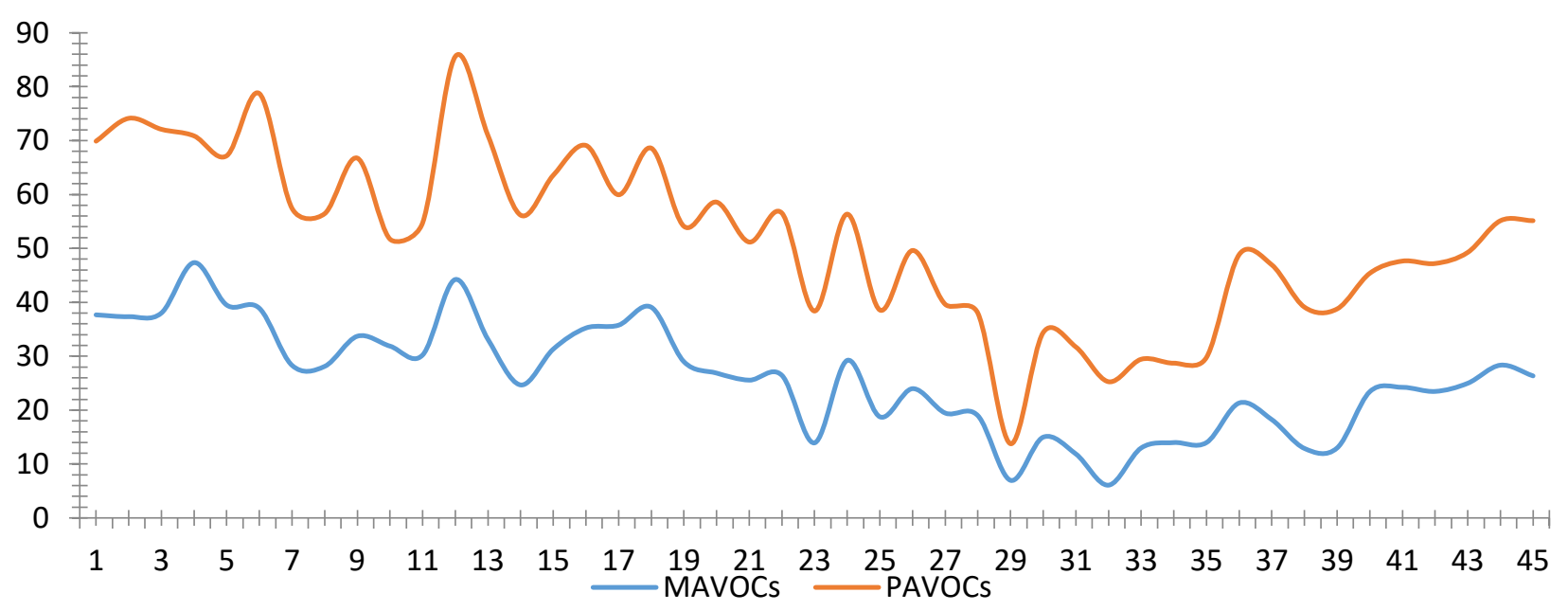

Figure 2. Line Plot of VOCs predicted VS VOCs measured $\left(\mu \mathrm{g} / \mathrm{m}^{3}\right)$

The values of predicted VOCs concentrations $\left(\mu \mathrm{g} / \mathrm{m}^{3}\right)$ are identified from measured data and the VOCs concentration values show the positive prediction for most of the samples by the developed model.

An expected rule of thumb is that outcomes with a Cook's distance of more than 3 times the mean, $\mu$, is a possible outlier. An alternative observation is to consider any point over $4 / n$, where $\mathrm{n}$ is the number of observations. Comparison of obtained prediction with observed values showed that the developed model indicated good performance in estimating VOCs concentration. Among the 45 weekly samples, only two outliers were identified (Table 4). Records with large cook's distance values are highly influential; such records may distort the model accuracy. Cook's distance, $\mathrm{D}_{\mathrm{i}}$, is used in Regression Analysis to identify influential outliers in a set of predictor variables

\section{Variable contribution}


The generalized linear model (GLM), like PCA, holds that any observed response is a linear sum of multiple individual underlying responses. "In contrast to PCA but similar to correlation maps, when using GLM, the data are fitted to predetermined signal time courses instead of signals being extracted based on differences invariance (as is done with PCA). Briefly, GLM analysis can be represented mathematically as $X$ $=G \bullet \beta+e$, where $X$ is a vector representing the time course of a given data, $G$ is the design matrix containing the series of predetermined response functions, $\beta$ is a vector of coefficients representing the degree to which each response function contributes to the overall signal, and $e$ is random noise". This equation is solved at each pixel using a least-squares approach [28]. In the developed model predicting VOCs concentration $\mathrm{PM}_{2.5}$ and wind speed has the predator's importance compared to the other covariates Figure 3.

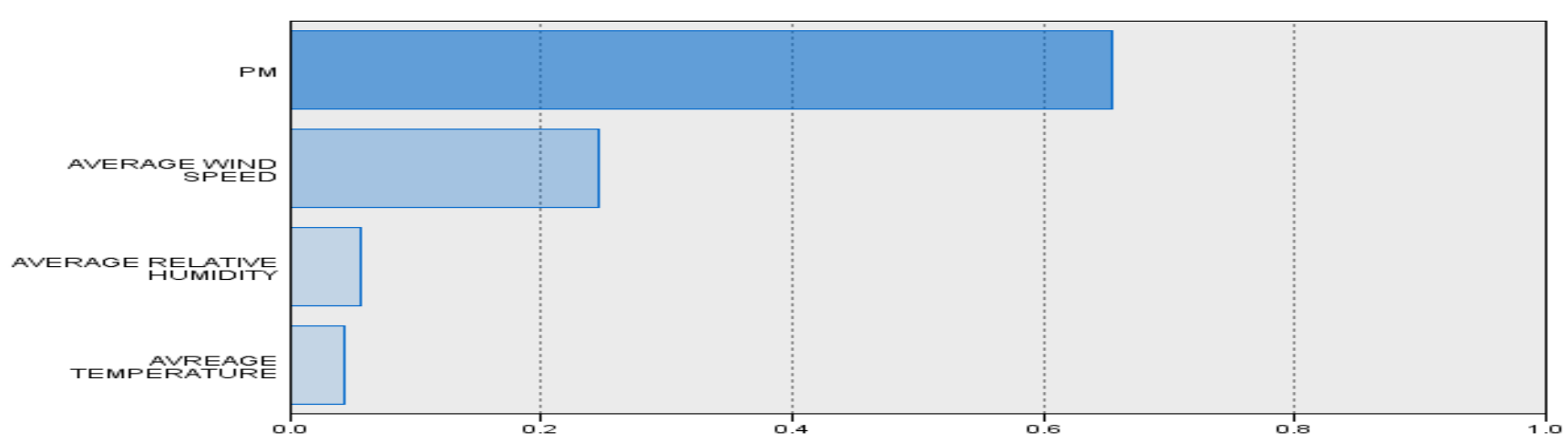

Figure 3: Contribution by each Covariates

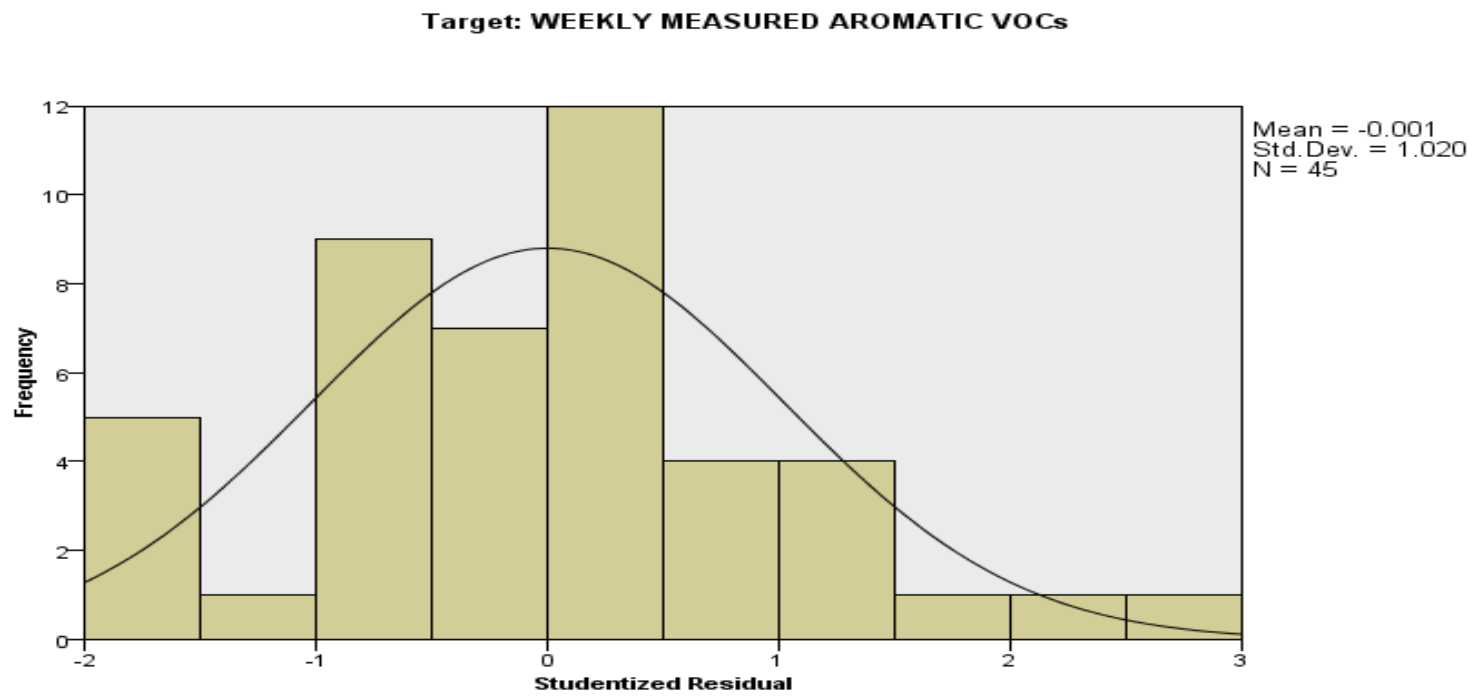

Figure 3: Normal Distribution 
Residuals distribution and normal distribution are compared in the studentized P-P plot of residuals (Figure 4). The diagonal line represents the normal distribution. The closer the observed cumulative residuals probabilities are to this line, the more the distribution of the residuals approaches the normal distribution.

The coefficients $\beta_{i}$ 's are the weights of the predictor variables (PM2.5, Temp, RH, and WV) in VOCs concentration. Thus, values of $\beta_{i}$ $>0$ imply that an increase in the predictor variables induces a corresponding increase in VOCs concentration and vice-versa. It is easy to see from the values of $\beta_{i}$ obtained from the results of the analysis of the model that VOCs concentration increases with increasing wind speed (WV) while increasing ambient temperature (Temp) reduces the concentration of predicted aromatic VOCs (PAVOCs), thus, when the temperature increases VOCs concentration reduces. Wind speed [WV] is another crucial variable that accounts for increased VOCs concentration; this may be

\section{References}

1. A. Guenther, T. Karl, P. Harley, C. Wiedinmyer, P. I. Palmer, and C. Geron (2012), Estimates of global terrestrial isoprene emissions using MEGAN (Model of Emissions of Gases and Aerosols from Nature), Atmos. Chem. Phys, 6, 3181-3210

2. G.C. Pratt, K. Palmer, C.Y. Wu, F. Oliaei, C. Hollerbach and M.J. Fenske (2000). An assessment of air toxics in Minnesota. Environ Health Perspect. 108, 815-825

3. T.J. Woodruff, D.A. Axelrad, J. Caldwell, R. Morello, A.Rosenbaum. (1999) Public health implications of 1990 air toxics concentrations across the United States. Environ Health Perspect, 106, 245-251.

4. R.G. Derwent, D.R. Middleton, R.A. Field, M.E. Goldstone, J.N. Lester and R. Perry (1995). Analysis and Interpretation of Air-Quality Data from an Urban Roadside Location in Central London over the period from July 1991 to July 1992. Atmos. Environ. 29, 923 946. because physical-chemical reaction for secondary particles formation could be enhanced by a major wind speed by increasing the mixing ratio of precursor gases. This trend is observed for the developed model. It is also observed for model A (PAVOCs) concentration decline with increasing $\mathrm{PM}_{2.5}$ and $\mathrm{RH}$. The relationship between RH and Temp results in an inverse indirect effect on the concentration of VOCs; because the increase in Temp generally results in lower RH.

\section{Conclusion}

Air Quality model to predict VOCs concentration in the outdoor environment was developed. The model developed is based on the relationship and interactions between the atmospheric concentration of air pollutants and meteorological variables using generalized linear models (GLM). A comparison of the obtained prediction with observed values showed that the developed model indicated good performance in estimating VOCs concentration.

5. P.W.G. Liu, Y.C. Yao, J.H. Tsai, Y.C. Hsu, L.P Chang and K.H. Chang (2012). Source Impacts by Volatile Organic Compounds in the Industrial City of Southern Taiwan. Sci. Total Environ. 398, 154-163.

6. B. Yuan, M. Shao, S.H. Lu and B. Wang (2010). Source Profiles of Volatile Organic Compounds Associated with Solvent Use in Beijing, China. Atmos. Environ. 44, 1919-1926.

7. A. Srivastava, A.E Joseph, S. Patil, A. More, R.C. Dixit, M. Prakash (2005). Air toxics in ambient air of Delhi. Atmos Environ 39, 59-71

8. E. Cetin, M. Odabasi and R. Seyfioglu (2003). Ambient volatile organic compound (VOC) concentrations around a petrochemical complex and a petroleum refinery. Sci Total Environ 312, 103-112

9. U.S. Environmental Protection Agency (1999). Determination of Volatile Organic Compounds (VOCs) in Air Collected in Specially Prepared Canister and Analyzed by Gas Chromatography/Mass Spectrometry 
(GC/MS), Second Edition Compendium Method TO-15.

10. U.S. Environmental Protection Agency (1996). Hazardous Air Pollutes (HAPs) List.

11. Y.H Liao, H.S. Yu, C.K. Ho, M.T. Wu, C.Y. Yang, J.R. Chen and C.C. Chang (2004). Biological Monitoring of Exposures to Aluminum, Gallium, Indium, Arsenic, and Antimony in Optoelectronic Industry Workers. Occup. Environ. Med. 46, 931-936.

12. Ladou, J. and Bailar, J.C. (2007). Cancer and Reproductive Risks in the Semiconductor Industry. Int. J. Occup. Environ. 13, 376-385

13. R. Chen, C. Chu, J.Tan, J. Cao, W Song and $\mathrm{X}$. Xu (2010). Ambient air pollution and hospital admission in Shanghai, China. J Hazard Mater, 181, 1:234-240.

14. R.A. Johnson and D.W Wichern (2007). Applied multivariate statistical analysis. 6th. New Jersey: Prentice-Hall.

15. J. Bogner and P. Scott (2001). Landfill $\mathrm{CH}_{4}$ Emissions: Guidance for Field Measurements. In: Lagerkvist, A., Ed., 1992-1994 IEA Landfill Gas Activity

16. A. Ighodaro, B. Anegbe and J.M. Okuo (2015). Emission Levels of Volatile Organic Compounds from Open Dumpsite in Benin Metropolis. Nigeria Journal of Applied Sciences 33:253-264

17. A.D. Nikolaou, G. Golfinopoulos, M.N. Kostopoulou, G.A. Kolokythas and T.D. Lekkas, (2002). Determination of Volatile Organic Compounds in Surface Waters and Treated Wastewater in Greece, Water Res. 36, 2883-2890.

18. H.A. Khwaja and A. Narang (2008). Carbonyls and NonMethane Hydrocarbons at a Rural Mountain site in the Northeastern United States, Chemosphere 71, 2030-2043.

19. H.C Nian, H.W. Liu, B.Z. Wu, C.C Chang, K.H. Chiu and J.G. Lo (2008). Impact of Inclement Weather on the Characteristics of Volatile Organic Compounds in Ambient Air at the Hsinchu Science Park in Taiwan. Sci. Total Environ, 399, 41- 49.

20. C.J. Cai, F.H. Geng, X.X.Tie, Q.O Yu and J.L An (2010). Characteristics and
Source Apportionment of VOCs measured in Shanghai China, Atmos. Environ. 44, 5005-5014

21. M. Leuchner and B. Rappengluck (2010). VOC SourceReceptor Relationships in Houston During TexAQS-II. Atmos. Environ. 44, 40564067.

22. E. Vega, G. Sanchez-Reyna, V. MoraPerdomo, G.S. Iglesias, J.L. Arriaga, T. Limon-Sanchez, S. Escalona-Segura and E. Gonzalez-Avalos (2011) Air Quality Assessment in a Highly Industrialized Area of Mexico: Concentrations and Sources of Volatile Organic Compounds. Fuel 90: 3509-3520.

23. C.Y. Peng, S.L. Hsiao, C.H. Lan and Y.L. Huang (2013). Application of Passive Sampling on Assessment of Concentration Distribution and Health Risk of Volatile Organic Compounds at a High-tech Science Park. Environ. Monit. Assess, 185, 181-196.

24. J.M. Garcia, F. Teodoro, R. Cerdeira, L.M. Coelho, R. Prashant, M.G. Kumar and A. Carvalho (2016). Developing a methodology to predict PM10 concentrations in urban areas using Generalized Linear Models. Environmental Technology DOI: 10. 1080/09593330.2016.1149228

25. G.M.S. Conceição, P. H. N. Saldiva and J. M. Singer (2001), MLG and MAG models to analyze the association between air pollution and morbidity and mortality markers in data from the city of São Paulo. Rev. Bras. Epidemiol 4: 206-224

26. R.H. Brown, M.D. Wright and N.T. A plant (1999). The use of diffusive sampling for monitoring of Benzene, Toluene and Xylene in ambient air. Pure Applied Chemistry. 10, 19- 28.

27. J.M. Okuo, C. Ojiodu and E. Olumayede (2013). Volatile organic compounds (VOCs) pollution in Iganmu industrial area, Lagos State, Southwestern Nigeria, Journal of Biotechnology 2, 4 43-49

28. P. Nader and W.T. Arthur (2002). Optical Imaging Based on Intrinsic Signals in Brain Mapping: The Methods (Second Edition) 